\title{
Accuracy of Sonographic Fetal Weight Estimation within 14 Days of Delivery in a Jordanian Population Using Hadlock Formula 1
}

\author{
Asma S. Basha ${ }^{a} \quad$ Ilham B. Abu-Khader ${ }^{b}$ Rawan M. Qutishat ${ }^{a}$ Zouhair O. Amarin $^{c}$ \\ a Department of Obstetrics and Gynecology, The University of Jordan, Amman, b Department of Nursing, Jordan \\ University Hospital, Amman, and ' ${ }^{\mathrm{D}}$ Department of Obstetrics and Gynecology, Jordan University of Science and \\ Technology, Irbid, Jordan
}

\section{Key Words}

Sonography · Fetal weight estimation · Hadlock formula 1

\begin{abstract}
Objectives: To assess the accuracy of sonographic fetal weight estimation within 14 days of delivery in a Jordanian population using Hadlock formula 1 in the third trimester. Materials and Methods: Estimated fetal weights and actual fetal weights data were collected from the medical records of pregnant women who had undergone sonographic fetal weight estimation within 14 days of delivery over the period of March 2008 to June 2010. The analysis included 409 Jordanian women; 6 of them had twins, so the study involved estimation of 415 fetal weights, and these were compared to the actual recorded neonatal weights. Using Hadlock formula 1, we compared the estimations with the infants' actual birth weights. The data were analyzed in 2 groups: within 7 days and 8-14 days. Results: The mean estimated fetal weight was 3,133 $\pm 475 \mathrm{~g}$ (range 1,343-4,420 g). The mean actual birth weight was $3,179 \pm 450 \mathrm{~g}$ (range 1,300-4,450 g). The mean absolute percentage of error of ultrasound fetal weight estimation for all infants was 6.5\%; however, it was 6.1 and $8.2 \%$ if the fetus was delivered within 7 days or 8-14 days of sonography, respectively. Overall, $78.8 \%$ of fetal weight estimations were within $10 \%$ of actual birth weight;
\end{abstract}

however it was 81.3 and $69.9 \%$ if the fetus was delivered within 7 days or from 8-14 days of sonography, respectively. Conclusion: The use of Hadlock formula 1 for sonographic fetal weight estimations in Jordanian women showed acceptable results relative to the actual neonatal weight at birth. However, fetal weight estimation was more reliable when performed within 7 days of delivery.

Copyright $\odot 2012$ S. Karger AG, Basel

\section{Introduction}

Neonatal weight is an important predictive parameter of neonatal outcome, and its estimation is valuable in planning the mode of delivery and obstetric management of labor [1]. Also, when dealing with anticipated preterm delivery, perinatal counseling on likelihood of survival, the intervention undertaken to postpone preterm delivery, optimal route of delivery, or the hospital where delivery should occur may be based wholly or in part on the estimation of expected birth weight $[2,3]$.

The estimation of fetal weight by ultrasound uses a regression formula to derive the birth weight after the measurement of various fetal structures $[4,5]$. Over the past 30 years, there have been many such published formulas that included Hadlock et al. [6] in the USA, a

\section{KARGER}

Fax +4161306 1234

E-Mail karger@karger.ch

www.karger.com (c) 2012 S. Karger AG, Basel

$1011-7571 / 12 / 0214-0366 \$ 38.00 / 0$

Accessible online at:

www.karger.com/mpp
Dr. Asma S. Basha

Department of Obstetrics and Gynecology, Faculty of Medicine

University of Jordan and Jordan University Hospital

PO Box 13046, Amman 11942 (Jordan)

Tel.+962 795669 727, E-Mail asmbasha2001@yahoo.com 
group in Germany [7], and Campbell and Wilkin [5] and Shepard et al. [8] in Great Britain. In other countries, various formulas are used depending on the center involved. The accuracy of predicting birth weight by a variety of different formulas, incorporating different ultrasonic measurements, has been studied extensively [9]. It has been reported that the highest correlation coefficient $(0.914,0.921)$ and the most stable results between estimated fetal weight and birth weight in all widely accepted formulas for fetal weight estimation was generated with Hadlock formulas 1 and 2, respectively [7]. Hoopmann et al. [10] tested weight formulas, specifically designed for very small fetuses, and concluded that the use of Hadlock formulas is good. Venkat et al. [11] also tested the Hadlock formula in a south-east Asian population and concluded that even though this formula was originally derived from an American Caucasian population, it was equally useful for other ethnic groups. However, this formula has not been validated in Jordan. Therefore, the aim of this study was to assess the accuracy of Hadlock formula 1 in sonographic fetal weight estimation during the third trimester, and the accuracy of sonographic fetal weight estimation within 14 days of delivery in a Jordanian population using Hadlock formula 1 .

\section{Materials and Methods}

Estimated fetal weight and actual neonatal weight were collected from the medical records from March 1st 2008 to June 30th 2010. The study consisted of fetuses in the third trimester who had undergone an ultrasound estimation of fetal weight during a routine visit to the Obstetric Clinic at Jordan University Hospital and who delivered within 14 days of the measurement. The analysis included 409 Jordanian women; 6 women had twin gestation (each fetus was considered independently). A total of 415 fetuses were examined, and they were divided into two groups, those who delivered within 7 days (332) and those who delivered after 7, but within 14 days of the estimation (83). $30 \mathrm{~g}$ were added per day to the estimated fetal weight to cover the interval between estimation and delivery.

All stillbirths and fetuses with congenital abnormalities and hydrops were not included in the 415 . Data were collected from the medical records in which maternal and infant information were present. All ultrasound measurements were performed by a single obstetric physician (A.B.) with fetomaternal sub-specialty training. Ultrasound measurement was carried out with a curvilinear abdominal transducer (3.5-5.0 MHz) using Philips HD-11 equipment. Estimation of fetal weight was determined using measurements of fetal head circumference, fetal abdominal circumference and fetal femur length. The fetal head measurements were made in the axial plane at the level where the continuous midline echo is broken by the cavum septum pellucidum in the anterior third. The head circumference was measured around the perimeter using an electronic ellipse as described by Campbell and Thoms $[12,13]$. The abdominal circumference was measured in the transverse axial view of the fetal abdomen at the level of the liver, identifying the spine and descending aorta posteriorly, the umbilical vein in the anterior third and the stomach bubble in the same plane; just above the level of the cord insertion measurements were taken around the perimeter as described by Campbell et al. $[7,8]$. The fetal femur length was measured in a view where the full femoral diaphysis was seen in a plane as close as possible to a right angle to the ultrasound beam; measurements were taken from one end of the diaphysis to the other, not including the distal femoral epiphysis [14]. Measurements were made with calibrated caliper on the machine on frozen images using the mapping method. Using Hadlock formula 1 and the measured head circumference (HC), abdominal circumference (AC) and fetal femur length (FL), the estimated fetal weight (EFW) was calculated using the formula shown below:

$$
\begin{aligned}
& \log _{10} \mathrm{EFW}=1.326-0.00326(\mathrm{AC})(\mathrm{FL}) \\
& +0.0107(\mathrm{HC})+0.0438(\mathrm{AC})+0.158(\mathrm{FL}) .
\end{aligned}
$$

Neonatal weights were recorded soon after birth by the on duty staff nurses at the delivery room following neonatal resuscitation (if required). The weights were rounded to the nearest $50 \mathrm{~g}$ using regular baby scale (Misaki).

\section{Statistical Analysis}

All statistical analyses were carried out with SPSS statistical software, version 17 (SPSS Inc., Chicago, Ill., USA). The difference between the estimated fetal weight and the actual neonatal weight (simple error) was recorded as error in grams. The percentage error was calculated using the following equation: percentage error $=($ estimated weight - neonatal weight $) \times 100 /$ neonatal weight.

Negative values for percentage error indicated that the estimated fetal weight was underestimated, and positive values indicated that it was overestimated. The absolute percentage error was defined as absolute value.

In addition, the Bland and Altman method was used for evaluating agreement between the two measurements (estimated and actual weights). Linear regression analysis for parametric data was used and statistical significance was stated at the $5 \%$ level. Data are presented as mean \pm SD.

\section{Results}

The mean estimated fetal weight was 3,133 $\pm 475 \mathrm{~g}$ (range 1,343-4,420). The mean actual birth weight was $3,179 \pm 450 \mathrm{~g}$ (range 1,300-4,450). The mean time interval between ultrasound estimation of fetal weight and delivery was $4.1 \pm 3.9$ days $(\mathrm{n}=415)$, and it was $2.4 \pm 2.2$ for time interval less than 7 days and $10.6 \pm 2$ for $8-14$ days of estimation. The average gestational age on estimation was 37.8 (29-41) weeks and the average neonatal gestational age on delivery was 38.5 (29-42) weeks. 


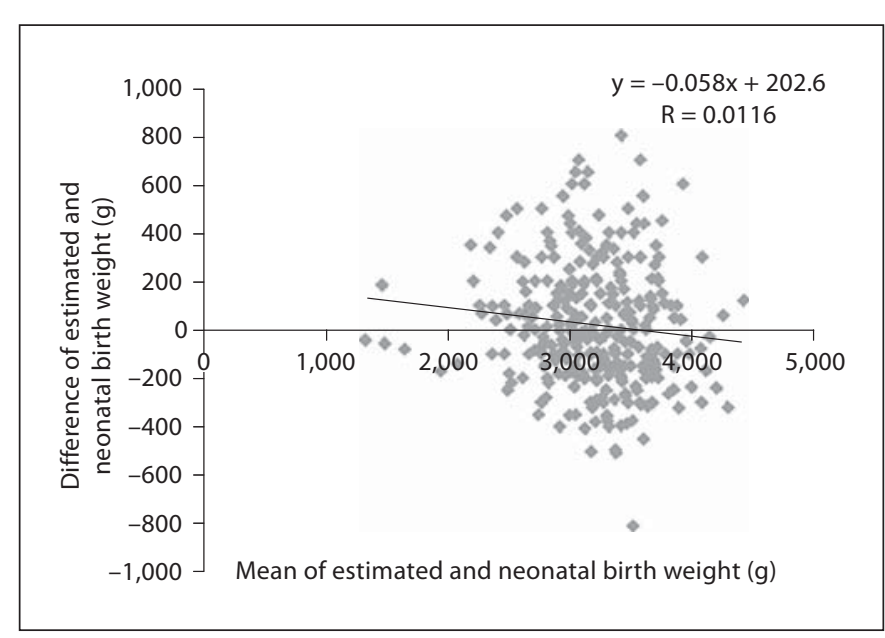

Fig. 1. Bland and Altman plot of 332 paired women on estimated birth weight and neonatal weight within 7 days between estimation and birth. $\mathrm{R}=0.0116(\mathrm{p}<0.01)$, slope $=-0.198(\mathrm{p}=0.05)$, intercept $=3,175(\mathrm{p}=0.05)$.

Table 1. Analysis of ultrasound fetal weight compared to neonatal weight at variable time intervals between estimation and birth

\begin{tabular}{lcc}
\hline Parameters & $\begin{array}{l}\text { Within 7 days } \\
(\mathrm{n}=332)\end{array}$ & $\begin{array}{l}\text { Within 8-14 days } \\
(\mathrm{n}=83)\end{array}$ \\
\hline GA on estimation, weeks & $38.1 \pm 1.5$ & $36.8 \pm 1.5$ \\
Estimated fetal weight, g & $3,163 \pm 482$ & $3,014 \pm 426$ \\
GA at birth, weeks & $38.5 \pm 1.5$ & $38.4 \pm 1.5$ \\
Neonatal birth weight, g & $3,180 \pm 456$ & $3,173 \pm 427$ \\
Absolute difference, g & $193 \pm 154$ & $264 \pm 174$ \\
Weight difference, \% & $6.2 \pm 5.3$ & $9.0 \pm 6.3$ \\
Actual percentage error & $-0.4 \pm 7.7$ & $-4.7 \pm 8.5$ \\
Absolute percentage error & $6.1 \pm 4.7$ & $8.2 \pm 5.2$ \\
\hline
\end{tabular}

$\mathrm{GA}=$ Gestational age.

The mean absolute error for sonographic fetal weight estimations made $\leq 7$ days prior to delivery was $6.1 \pm 4.7$ ( $\mathrm{n}=332)$; however, these tended to result in a slight underestimation of fetal weight if they were carried out 8-14 days prior to delivery, the mean absolute error was $8.2 \pm$ $5.2(\mathrm{n}=83)($ table 1$)$.

The sonographic fetal weight estimation correlated significantly with actual birth weight for all infants who delivered within 7 days of estimation $(\mathrm{R}=0.0116, \mathrm{p}<$ 0.01 ) (fig. 1). Of these fetal weight estimations, $81.3 \%$ were within $10 \%$ of the actual birth weight. However, the sonographic estimation of fetal weight correlated to a lesser

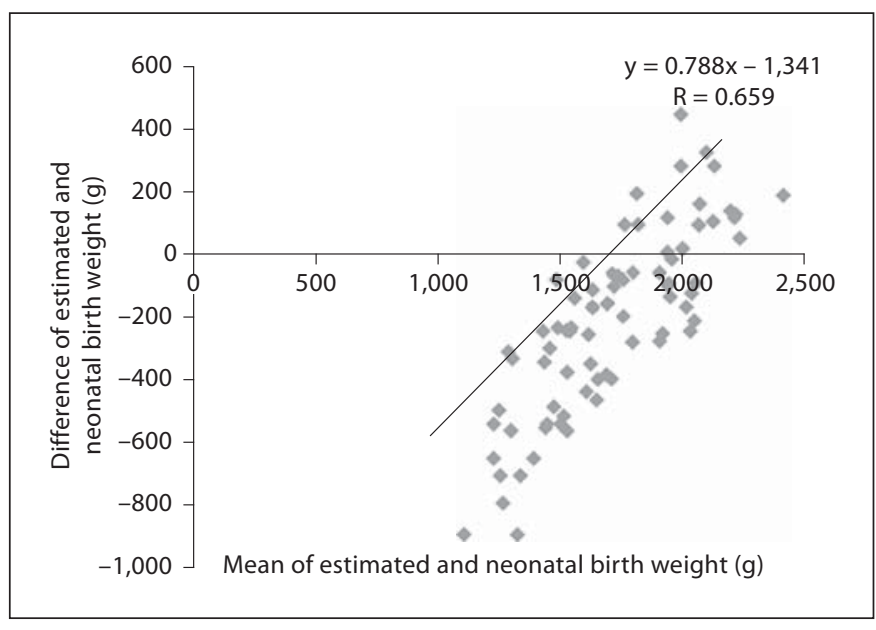

Fig. 2. Bland and Altman plot of 83 women with estimated birth weight and neonatal weight within $8-14$ days between estimation and birth. $\mathrm{R}=0.659(\mathrm{p}<0.01)$, slope $=-0.835(\mathrm{p}<0.01)$, intercept $=1,641(\mathrm{p}=0.00)$.

degree with the actual birth weight for all infants who were delivered between 8-14 days of estimation ( $\mathrm{R}=$ $0.659, \mathrm{p}<0.01$ ) (fig. 2). Of all fetal weight estimations, $69.9 \%$ were within $10 \%$ of actual birth weight.

\section{Discussion}

The problem with reliance on ultrasound estimates of fetal weight is that it has inherent inaccuracies, with large intra- and interobserver variability $[7,15]$. The absolute percentage errors of $6.1 \%$ of delivery within 7 days and $8.2 \%$ within $8-14$ days are comparable to other studies [2, $6,16-19]$. Equally, the $81.3 \%$ of neonatal weight estimations that were within $10 \%$ of actual neonatal weight if the fetus delivered within 7 days of estimation, and $69.9 \%$ after 8-14 days are also comparable to other studies [2, 6, 16-19]. In an extensive systematic review, Dudley [15] stated that the method of Hadlock et al. [6] generally provided more consistent mean systematic errors.

Our study confirmed the previous reports of Chauhan et al. [9] and Peregrine et al. [19] that the accuracy of prediction is significantly higher when the fetal weight estimation was performed within 7 days of delivery. The high yield of correlation coefficients in this study, when delivery was within 7 days of fetal weight estimation, and acceptable yield when the fetus was delivered between 8 and 14 days of estimation, confirmed those of other studies $[20,21]$ and is explained by con- 
tinuous fetal growth as time elapses between sonography and delivery.

The major limitations of this study were its retrospective nature. All the data were not available; hence a table of the baseline characteristics such as parity, maternal BMI, medical conditions such as diabetes and chronic hypertension could not be included. The other limitation was that the predictive value for small or large weight for gestational age was not calculated as this predictive value is more important clinically.

\section{Conclusion}

The use of Hadlock formula 1 to estimate sonographic fetal weight in Jordanian women within 14 days of delivery showed acceptable results relative to the actual neonatal weight. However, fetal weight estimation gave better results when it was performed within 7 days of delivery.

\section{Disclosure Statement}

The authors declare that they have no conflict of interest.

\section{References}

1 Nahum G: Estimation of fetal weight: http:// www.emedicine.com, March 2003.

$\checkmark 2$ Chauhan SP, Hendrix NW, Magann EF, Morrison JC, Jenney SP, Devoe LD: Limitations of clinical and sonographic estimates of neonatal weight: experience with 1034 parturients. Obstet Gynecol 1998;91:72-77.

-3 Hendrix NW, Grady CS, Chauhan SP: Clinical versus sonographic estimates of birth weight in term of parturients. A randomized clinical trial. J Reprod Med 2000;45:317-322.

-4 Mirghani HM, Weerasinghe S, Ezimokhai M, Smith JR: Ultrasonic estimation of fetal weight at term: an evaluation of eight formulae. J Obstet Gynaecol 2005;31:409-413.

5 Campbell S, Wilkin D: Ultrasonic measurement of fetal abdomen circumference in the estimation of fetal weight. Br J Obstet Gynaecol 1975;82:689-697.

-6 Hadlock F, Harrist R, Sharman R, Deter R, Park S: Estimation of fetal weight with the use of head, body and femur measurements. Am J Obstet Gynecol 1985;151:333-337.

7 Kurmanavicius J, Burkhardt T, Wisser J, Huch R: Ultrasonographic fetal weight estimation: accuracy of formulas and accuracy of examiners by birth weight from 500 to 5,000 g. J Perinat Med 2004;32:155-161.
-8 Shepard M, Richards V, Berkowitz R, Warsof S, Hobbins J: An evaluation of two equations for predicting fetal weight by ultrasound. Am J Obstet Gynecol 1982;142:47-54.

-9 Chauhan SP, Hendrix NW, Magann EF, Morrison JC, Scardo JA, Berghella V: A review of sonographic estimate of fetal weight: vagaries of accuracy. J Matern Fetal Neonatal Med 2005;18:211-220.

10 Hoopmann M, Bernau B, Hart N, Schild RL, Siemer J: Do specific weight formulas for fetuses $<$ or $=1,500$ g really improve weight estimation? Ultraschall Med 2010;31:48-52.

11 Venkat A, Chinnaiya A, Gopal M, Mongelli JM: Sonographic fetal weight estimation in a south-east Asian population. J Obstet Gynaecol Res 2001;27:275-279.

12 Pineau JC, Grange G, Kapitaniak B, Vayssiere C, Tomikowski J, Guihard-Costa AM: Estimation of fetal weight: accuracy of regression models versus accuracy of ultrasound data. Fetal Diagn Ther 2008;24:140 145.

13 Campbell S, Thoms A: Ultrasound measurement of the fetal head to abdomen circumference ratio in the assessment of growth retardation. Br J Obstet Gynaecol 1977;84:165174.

14 Chitty LS, Altman DG, Henderson A, Campbell S: Charts of fetal size: femur length. $\mathrm{Br} \mathrm{J}$ Obstet Gynaecol 1994;101:132-135.
15 Dudley NJ: A systematic review of the ultrasound estimation of fetal weight. Ultrasound Obstet Gynecol 2005;25:80-89.

16 Nahum GG, Stanislaw H: Ultrasonographic prediction of term birth weight: how accurate is it? Am J Obstet Gynecol 2003;188: 566-574.

17 Houzé de l'Aulnoit A, Closset E, Deruelle P: Accuracy of ultrasound estimated fetal weight performed by OB-Gyn residents at due date. Gynecol Obstet Fertil 2009;37:367371.

18 Anderson G, Jolley J, Wells E: Sonographic estimation of fetal weight: comparison of bias, precision and consistency using 12 different formulae. Ultrasound Obstet Gynecol 2007;30:173-179.

19 Peregrine E, O’Brien P, Jauniaux E: Clinical and ultrasound estimation of birth weight prior to induction of labor at term. Ultrasound Obstet Gynecol 2007;29:304-309.

20 Owen P, Donnet ML, Ogston SA, Christie AD, Howie PW, Patel NB: Standards for ultrasound fetal growth velocity. Br J Obstet Gynaecol 1996;103:60-69.

21 Chien PFW, Owen P, Khan KS: Validity of ultrasound estimation of fetal weight. J Obstet Gynecol 2000;95:856-860. 